\title{
Message from the President
}

\section{Assalaamu Alaykum}

\section{Dear IMANA Members:}

It is a privilege and an honor for me to serve you as the president of this organization. Although IMANA Executive Council members volunteer their time, energy, and money to serve the association, IMANA recognizes that you have put your trust in the organization. During this year, the Executive Council and I will promote the goals and mission of IMANA, inshaallah.

The Executive Committee has started working on many projects. Please visit the web site to get familiar with the Executive Committee members. We are very excited about launching our new and improved IMANA web site. Please give us your feedback.

The Relief Committee, under the leadership of Dr. Ismail Mehr, has made IMANA known for disaster and medical relief work in Haiti and most recently in Pakistan. Currently, we are focusing on rehabilitation of the Pakistan flood victims, providing hand pumps for clean drinking water and tents and other basic supplies to help the victims face the coming winter. For details of our previous projects please visit the IMANA web site.

Dr. Khalique Zahir and his team of plastic surgeons and anesthesiologists went to Khartoum, Sudan, earlier this year for a cleft lip and palate repair camp and later for a vesicovaginal fistula repair camp. Another cleft lip/palate project is planned for the end of this year.

We are also considering having educational seminars and hands-on training camps to train local physicians in African and other countries. Any member interested in participating is welcome to contact IMANA headquarters.

The Public Health Committee, under the leadership of Dr. Maqbool Haq, has developed brochures in four different languages (English, Arabic, Spanish, Urdu) as a guide to good health practices. An IMANA guide to starting a charity clinic, Charity 101, is also available on the IMANA web site. This year, with Dr. Azam Kundi as cochair, other charity health-care related projects for North America, such as healthy lunch programs for schools, are evolving.
The IMANA Ethics Committee, under the leadership of Dr. Hossam Fadel and Dr. Faroque Khan, cosponsored a highly successful two-day conference on September $17-18$ on ethics of end-of-life issues, in collaboration with Hofstra University, in New

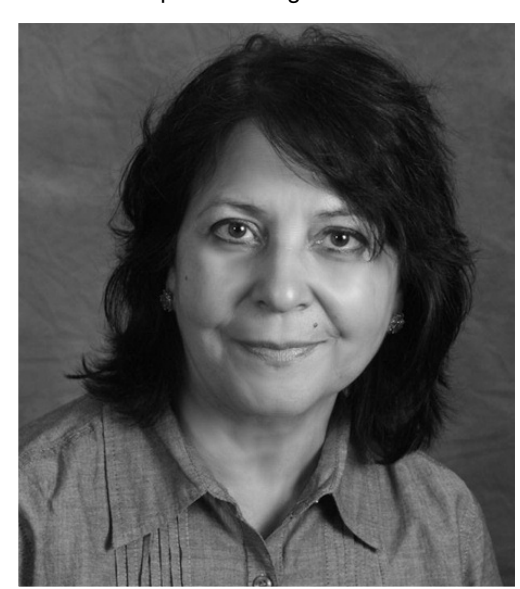

Abida Haque, MD York. Many other papers on ethics are available on the IMANA web site.

Dr. Farida Khan and Dr. Ali Nadroo, Education Committee chair and cochair, are planning seminars for next year's Islamic Society of North America (ISNA) meeting in collaboration with the Resident's Committee chair, and compiling a list of speakers for seminars and continuing medical education (CME) meetings. Committee members are also planning to develop/procure modules for assessment and treatment of common diseases for possible distribution to Islamic medical associations in developing countries.

The CME Committee had an outstanding CME program in Istanbul, Turkey, with close to 170 attendees. IMANA is very close to getting accredited for CME by the Accreditation Council for Continuing Medical Education (ACCME), thanks to the tireless work of the CME Chair Dr. Ayaz Samadani and Ms. Helen Allen. Another excellent CME program is being developed for the 2011 Annual Convention in San Juan, Puerto Rico.

The Student/Resident Committee, under the leadership of Dr. Tarannum Lateef and Dr. Naveed Akhter, organized two highly successful events last year. This year, Dr. Tarannum Lateef and cochair Dr. Omar Lateef are planning a pre-ISNA student/resident seminar for 2011, and a medical seminar for the ISNA meeting, in collaboration with the Education Committee.

Dr. Zahir, immediate past president of IMANA, started the Legislative Action/Advocacy Committee last year, which is actively involved in health care reform and other health care issues. The committee 
will continue to work on these important issues this year.

A newly formed Grants Committee, under the leadership of Dr. Zahir and Dr. Sheik Nasir Hassan, has started to work on getting IMANA positioned for applying for grants. We would appreciate help from those members experienced in grant writing to volunteer for this committee.

During my term as president of IMANA, I hope to address the needs of medical students and residents by providing an active web site link for the Young Professionals Network (YPN), where they can interact and get valuable information regarding medical schools and residencies.

Our membership is increasing, thanks to the hard work of Dr. Arfa Khan, the past Membership Committee chair. This year, the Membership Committee Chair Dr. Imran Qureshi and cochairs Dr. Arif Rizvi and Dr. Fadia Abaza have started to reach out to the Muslim physician community to encourage individuals to become members of the IMANA. The strength of any organization is in its membership. I would urge all members and nonmembers to become active participants in IMANA, visit the new web site and invite others to become members.

The IMANA journal JIMA, thanks to the hard work of Dr. Hossam Fadel, continues to provide informational articles and case reports from the
United States and from the international IMA members. I urge all members, especially the speakers of the recent Annual Convention in Turkey, to submit their manuscripts to JIMA.

Local chapters of IMANA are becoming actively involved in many activities. We would like to see many more local chapters established in different parts of the country. IMANA Headquarters can assist anyone interested in starting a local chapter in their community.

Last, but not the least, I want to thank the past leadership of IMANA for its diligence and hard work to strengthen IMANA. I am grateful to the current leaders for support and look forward to working with them in the coming year. I pray that Allah ali gives us the guidance and wisdom to do the right things for our community and for humanity in general.

\section{Wassalam.}

\section{Respectfully,}
Abida Haque, MD
IMANA President
Professor of Pathology
The Methodist Hospital
Houston, Texas 